\title{
Changes in the Luminal Environment of the Colonic Epithelial Cells and Physiopathological Consequences
}

\author{
François Blachier, * Martin Beaumont, ${ }^{*}$ Mireille Andriamihaja, * Anne-Marie Davila, * Annaïg Lan, * Marta Grauso, * \\ Lucie Armand, ${ }^{*}$ Robert Benamouzig, ${ }^{* \dagger}$ and Daniel Tomé*
}

From the UMR Physiologie de la Nutrition et du Comportement Alimentaire, * AgroParisTech, INRA, Université Paris-Saclay, Paris; and the Department of Gastroenterology, ${ }^{\dagger}$ Avicenne Hospital, Assistance Publique-Hôpitaux de Paris, Bobigny, France

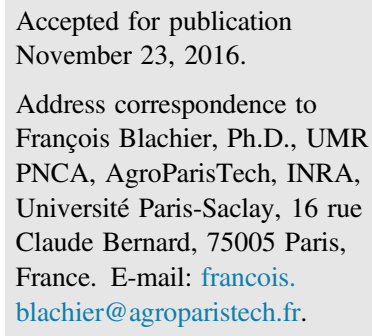

\begin{abstract}
Evidence, mostly from experimental models, has accumulated, indicating that modifications of bacterial metabolite concentrations in the large intestine luminal content, notably after changes in the dietary composition, may have important beneficial or deleterious consequences for the colonic epithelial cell metabolism and physiology in terms of mitochondrial energy metabolism, reactive oxygen species production, gene expression, DNA integrity, proliferation, and viability. Recent data suggest that for some bacterial metabolites, like hydrogen sulfide and butyrate, the extent of their oxidation in colonocytes affects their capacity to modulate gene expression in these cells. Modifications of the luminal bacterial metabolite concentrations may, in addition, affect the colonic $\mathrm{pH}$ and osmolarity, which are known to affect colonocyte biology per se. Although the colonic epithelium appears able to face, up to some extent, changes in its luminal environment, notably by developing a metabolic adaptive response, some of these modifications may likely affect the homeostatic process of colonic epithelium renewal and the epithelial barrier function. The contribution of major changes in the colonocyte luminal environment in pathological processes, like mucosal inflammation, preneoplasia, and neoplasia, although suggested by several studies, remains to be precisely evaluated, particularly in a long-term perspective. (Am J Pathol 2017, 187: 476-486; http://dx.doi.org/10.1016/j.ajpath.2016.11.015)
\end{abstract}

The colonic epithelium is a dynamic structure with a rate of renewal among the fastest in the body. This renewal is made possible through a lifelong and highly coordinated sequence of events starting with mitosis of pluripotent stem cells ${ }^{1}$ and ending with anoikis of fully mature cells in the colonic lumen. $^{2}$ The colonic epithelium, which is organized in crypts separated by a flat surface, is notably responsible for the physiological function of water and electrolyte absorption from the lumen to the bloodstream. This corresponds to the polarized structure of absorptive colonocytes, which are facing the luminal content. This latter is a complex and not fully characterized mixture of water, bacteria, undigested or partially digested dietary/endogenous compounds, and bacterial metabolites. The colonic epithelium can be viewed as a selective barrier in close proximity with this intestinal luminal content. ${ }^{3}$ Occasionally, the homeostatic processes of colonic epithelial self-renewing and/or epithelium normal functions are disrupted; and such alterations may be associated with different colonic physiopathological states, including diarrhea, ${ }^{4}$ mucosal inflammation, and preneoplasic/neoplasic lesions. ${ }^{5}$ The objectives of this article are: i) to illustrate the impact of the macronutrient composition of the diet on the characteristics of the large intestine luminal contents using typical examples, ii) to give an overview on the effects of changes of the luminal environment on colonic epithelial cell physiology and metabolism, with a focus on the effects of bacterial metabolites, and iii) to examine to what extent such changes, above the

Supported by the European Commission (My New Gut) grant 613979 (F.B.), INRA, AgroParisTech, and Université Paris-Saclay.

Disclosures: None declared. 
adaptive capacity of colonocytes, may have significant consequences for the gut health.

Regarding the recognition of microbial ligands by intestinal epithelial cells, and the effects of bacterial toxins (eg, colibactin, Bacteroides fragilis toxin, and fragilysin) on colonic epithelial cells, the readers are invited to refer to recent reviews ${ }^{3,6}$ because these important aspects will not be presented herein.

\section{Effects of the Diet on the Luminal Environment of the Large Intestine}

In the colon, bacteria metabolize undigested or partially digested substrates available from endogenous (digestive secretions, exfoliated cells, and mucins) and dietary sources. ${ }^{7}$ Human dietary intervention studies revealed that the macronutrient composition of the diet can affect the amount of metabolites produced by the microbiota in the large intestine. In fact, dietary undigestible polysaccharides increase the fecal concentration of short-chain fatty acids, ${ }^{8}$ whereas high-fat diets increase bile acid secretion in the small intestine that leads to high fecal concentrations of microbiota-derived secondary bile acids, such as deoxycholic acid. ${ }^{9}$ High-protein diets increase fecal concentrations of amino acid-derived bacterial metabolites, such as branched-chain fatty acids, phenolic compounds, hydrogen sulfide, and ammonia. ${ }^{10}$

Colonic luminal $\mathrm{pH}$ may also be modified by dietary changes. However, this latter parameter is not easily accessible in humans, and most values are recovered from measurement of $\mathrm{pH}$ in animal models. For instance, a high-protein diet, in association with increased ammonia concentration, increases the $\mathrm{pH}$ in the rat colon content after 2 days. ${ }^{11}$ In humans, most of the data referred to the effects of dietary changes on fecal $\mathrm{pH}$, which reflects the $\mathrm{pH}$ in the distal part of the large intestine (ie, rectum). Ingestion of nondigestible carbohydrates decreases the fecal $\mathrm{pH}$ in adults, ${ }^{12}$ whereas a high-protein and low carbohydrate diet will result in an increase. ${ }^{13}$

Collectively, these studies provide strong evidence that the human rectal environment (thus inferred from feces analyses) is dependent on the macronutrient composition of the diet.

Briefly, regarding the composition of the colonic microbiota, this complex parameter, although considered as globally stable at the individual level, ${ }^{14}$ can be rapidly affected by environmental modifications, notably from dietary origin. ${ }^{15}$ Concerning luminal substrate availability, there is evidence that this parameter plays a major role in determining the rate of production of bacterial metabolites. ${ }^{6,16,17}$

Modified luminal bacterial metabolite composition in inflammatory bowel diseases has previously been reported. ${ }^{18}$ However, it is often difficult to determine whether such modifications are causes and/or consequences of these diseases. In the same line of thinking, although intestinal microbiota dysbiosis has been reported in colorectal cancers, ${ }^{19}$ and role of selected bacteria has been anticipated ${ }^{20}$ it remains a hard task to determine what are the respective causal links between the bacterial composition/bacterial metabolic capacity/bacterial metabolite composition and the related pathophysiological situations.

In this overall complicated context, we review herein the effects of individual changes in the luminal environment (bacterial metabolite composition, $\mathrm{pH}$, and osmolarity) on colonic epithelial cells and their potential implications in several digestive diseases.

\section{Bacterial Metabolites and Colonic Epithelium Energy Metabolism}

The gastrointestinal tract consumes as much as $20 \%$ of the whole body oxygen consumption, although it represents approximately 5\% of total body weight. ${ }^{21}$ Postprandial hyperemia is concomitant with enhanced intestinal oxygen uptake from the arterial blood, presumably to fuel the digestive and absorptive processes. ${ }^{22}$ In contrast with the arterial partial pressure of oxygen, this latter parameter in the cecal luminal content is extremely low, not exceeding $1 \mathrm{mmHg} .{ }^{23}$ However, oxygen from the host intestinal tissue can diffuse into the lumen, resulting in a radial gradient of oxygen-tolerant bacteria from the tissue to the lumen.

In the gastrointestinal tract, the intestinal epithelial cells are characterized by high energy demand, notably because of the rapid renewal of the epithelium and associated anabolic metabolism, and the activity of $\mathrm{Na} / \mathrm{K}$ ATPase that allows sodium extrusion at the basolateral membranes. ${ }^{21}$

Modification of the partial pressure of oxygen inside colonocytes may affect their metabolism and physiology. ${ }^{24}$ In active inflammatory bowel diseases, a metabolic shift toward hypoxia is observed, serving as an endogenous alarm signal in colonocytes. ${ }^{25}$ Interestingly, when epithelial cells in the colon are challenged by hypoxia, up-regulation of the proto-oncogenes $c$-fos and $c$-jun is observed, ${ }^{26}$ reinforcing the view that hypoxia acts in colonocytes on genes related to important physiopathological functions. ${ }^{27}$

Absorptive colonic epithelial cells use fuel substrates from both luminal and blood origin. Fuels from arterial origin are mainly L-glutamine, L-glutamate, L-aspartate, and D-glucose. Short-chain fatty acids (namely, acetate, propionate, and butyrate) are major luminal fuels for colonocytes. They are produced by the microbiota from undigestible carbohydrates $^{28}$ and several amino acids originating from undigested proteins. ${ }^{29}$ Among short-chain fatty acids, butyrate is characterized by its capacity to inhibit endogenous substrate oxidation. ${ }^{30}$ Data showing that butyrate uptake is impaired in inflamed colonic mucosa suggest that the reduction of butyrate availability may decrease the physiological functions of this short-chain fatty acid in colonocytes. $^{31}$ In addition to acting as a luminal fuel in colonocytes, butyrate also acts as a regulator of gene expression in colonocytes ${ }^{32}$ (Figure 1). Mitochondrial metabolism of butyrate in colonocytes is likely a way to 
regulate the cytoplasmic concentration of this short-chain fatty acid, and then its inhibitory effect on histone deacetylase activity. Such inhibition is then responsible for increased histone acetylation, which affects gene expression in colonocytes. In addition, experiments with ${ }^{14} \mathrm{C}$-labelled butyrate indicate that butyrate acts as an acetyl-CoA donor for histone acetylation. ${ }^{32}$ Then, it appears that butyrate metabolism in colonocytes and its effects on gene expression are tightly connected (Figure 1). As reviewed by Hamer et $\mathrm{al},{ }^{28}$ the potential of butyrate to act, at least in experimental animal models, as a beneficial modulator in situations such as mucosal inflammation and colorectal carcinogenesis may rely partly on the butyrate ability to modulate gene expression in colonocytes and to affect key regulators of cell cycle, apoptosis, and associated signaling pathways.

Several other bacterial metabolites, including hydrogen sulfide, $p$-cresol, and ammonia, may interfere with colonocyte oxygen consumption in in vitro experiments. Hydrogen sulfide is produced by the microbiota from dietary and endogenous S-containing substrates. ${ }^{33}$ Hydrogen sulfide at excessive luminal concentrations inhibits markedly, although in a reversible way, the colonocyte oxygen consumption (Figure 2). This inhibition of cell respiration corresponds to the inhibition of the mitochondrial cytochrome $c$ oxidase activity. ${ }^{34}$ In addition, at concentrations $>1 \mathrm{mmol} / \mathrm{L}$, hydrogen sulfide dose dependently inhibits butyrate oxidation in human colonic epithelial cells, ${ }^{34}$ likely as a consequence of the inhibition of the mitochondrial respiratory chain. Reduced colonocyte oxygen consumption, as observed under poisoning of colonocytes with hydrogen sulfide, may provoke an imbalance between ATP production and utilization in colonocytes. However, at micromolar extracellular concentrations, hydrogen sulfide has been shown to represent a mineral fuel for colonocytes, $^{35}$ the first one in this category. This is made possible by the oxidation of hydrogen sulfide by the mitochondrial sulfide oxidizing unit (Figure 2). Although hydrogen sulfide allows the generation of ATP in colonocytes, it is likely that in healthy colonocytes, hydrogen sulfide is not primarily

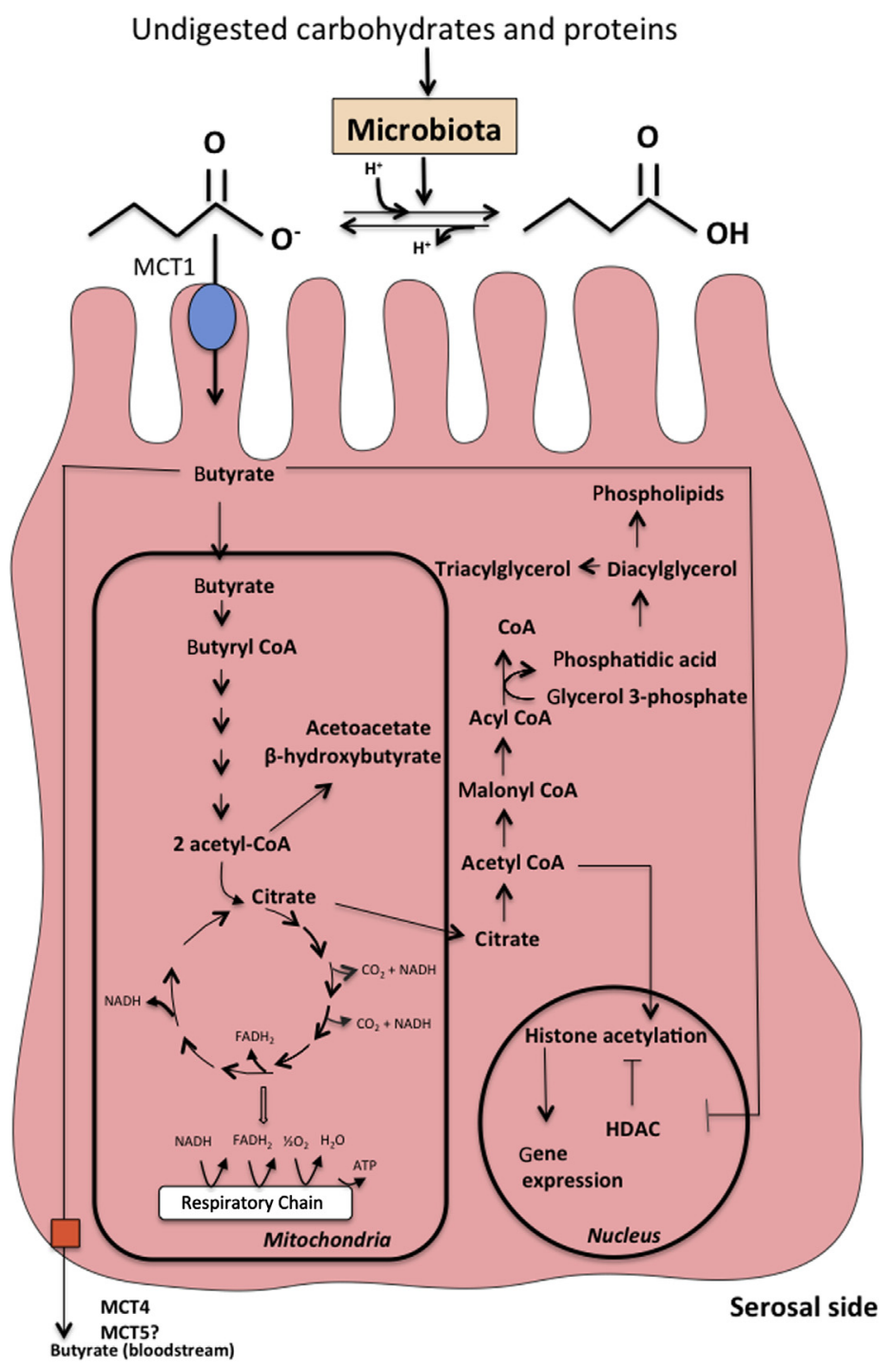

Figure 1 Schematic representation of the microbiotaderived butyrate metabolism and effects on colonocytes. Butyrate is produced from undigested carbohydrates and some protein-derived amino acids, diffusing through the mucus layers before being transported in its anionic form inside colonocytes through monocarboxylate transporter isoform 1 (MCT1) transporter, or diffusing in its neutral form in these cells. Butyrate is oxidized in the mitochondria, allowing ATP production. A part of cytosolic acetyl CoA produced from butyrate is used for lipid synthesis and histone acetylation, whereas unmetabolized butyrate inhibits histone deacetylase (HDAC) activity. Increased histone acetylation then modulates gene expression in colonocytes. The unmetabolized part of butyrate is then released in the bloodstream through the MCT transporters. 


\section{Undigested S-containing substrates}

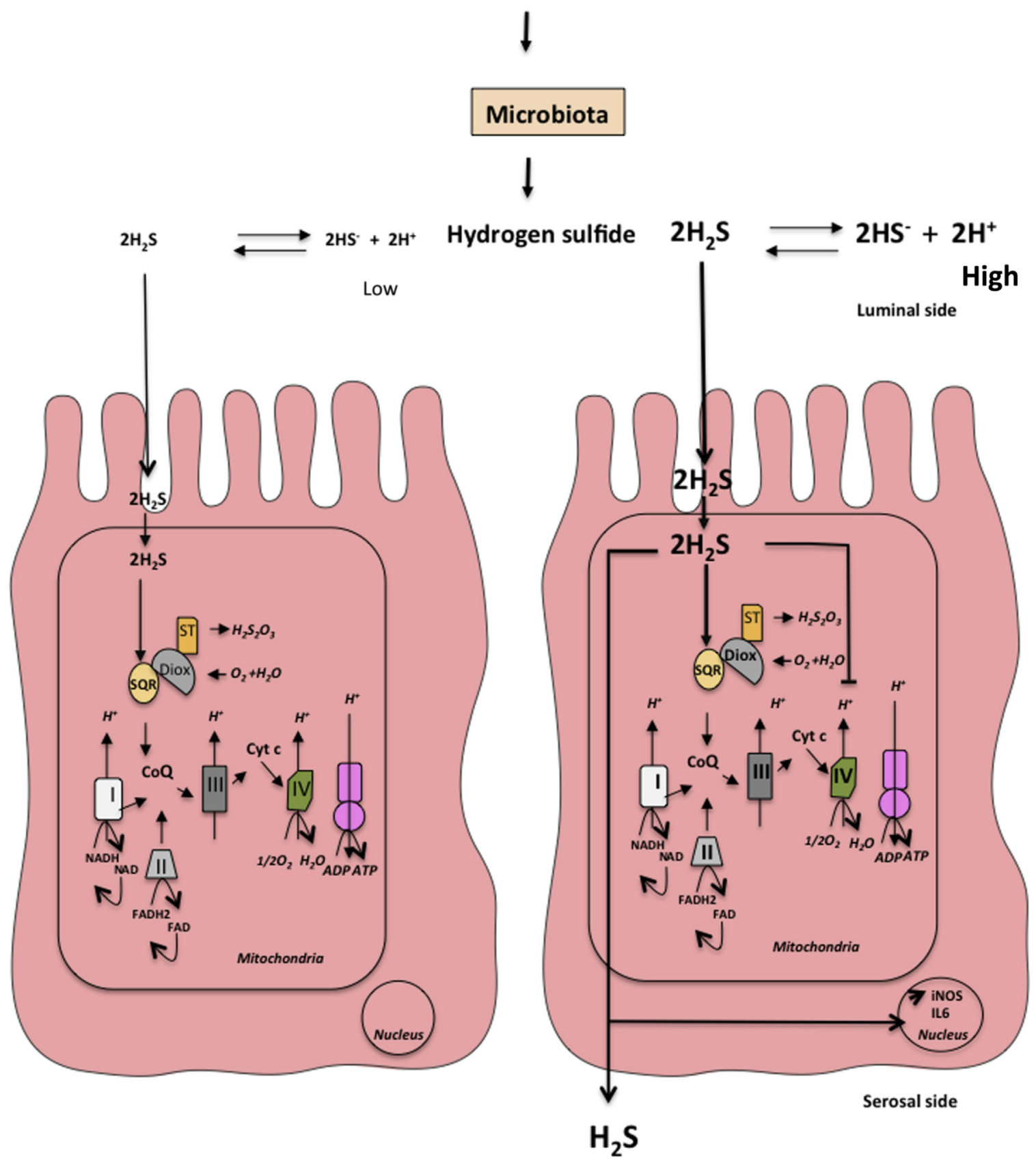

Figure 2 Schematic representation of the microbiota-derived hydrogen sulfide metabolism and effects on colonocytes. Hydrogen sulfide is produced from several dietary and endogenous sulfur-containing compounds, and diffuses through the mucus layers and colonocyte apical membrane. Left panel: When hydrogen sulfide concentration is low, mitochondria detoxicate it through oxidation into thiosulfate in the sulfide oxidizing unit [sulfide quinone reductase (SQR), dioxygenase ethylmalonic encephalopathy (Diox), and sulfur transferase (ST)] with ATP production. Right panel: When hydrogen sulfide is high, thus exceeding colonocyte detoxification capacity, it inhibits mitochondrial cytochrome (Cyt) $c$ oxidase activity, leading to a decrease in oxygen consumption. Increased concentration of the intracytoplasmic hydrogen sulfide increases the expression of genes related to inflammation. iNOS, inducible nitric oxide synthase.

oxidized to increase the cellular level of ATP above a steady-state value, but rather to allow its detoxification, thus regulating its intracellular concentration. ${ }^{36}$ At a concentration where hydrogen sulfide inhibits oxygen consumption in colonocytes, this gaseous compound increases the expression of several inflammation-related genes ${ }^{17}$; this raises the view that above the capacity of colonocytes to detoxify hydrogen sulfide in the mitochondria, the cytoplasmic concentration of this agent can increase and then affect gene expression in the nuclei (Figure 2). Interestingly, 
it has been shown that hydrogen sulfide produced endogenously maintains colon cancer bioenergetics, supporting colonic tumor growth. ${ }^{37}$

Another bacterial metabolite is $p$-cresol, which is produced by the intestinal microbiota from L-tyrosine, and which is present at a low millimolar concentration in the human feces. It inhibits partially oxygen consumption in human colonocytes in acute in vitro experiments, while increasing after pretreatment proton leak through the inner mitochondrial membrane (and thus decreasing mitochondrial bioenergetics activity and ATP cell content) with concomitant increase of the net production of anion superoxide. ${ }^{38}$ Anion superoxide can be generated within the mitochondrial respiratory chain, notably at two sites in complex $\mathrm{I}^{39}$ and $\mathrm{III},{ }^{40}$ particularly in situations of mitochondrial complex activity inhibition. Anion superoxide may affect cell physiology, notably by reacting with nitric oxide and forming the oxidant peroxynitrite. ${ }^{41}$

Ammonia (considered as the sum of $\mathrm{NH}_{4}^{+}$and $\mathrm{NH}_{3}$ ) is produced by the bacterial microbiota from amino acid deamination and urea hydrolysis, and is present at millimolar concentrations in the colonic luminal content. ${ }^{29} \mathrm{High}$ millimolar concentrations of ammonia inhibit short-chain fatty acid oxidation ${ }^{42}$ and basal oxygen consumption in colonic epithelial cells. ${ }^{43}$ However, colonocytes have the metabolic capacity to synthesize L-glutamine from ammonia and L-glutamate in the cytosol, and to synthesize carbamoylphosphate from ammonia and bicarbonate in the mitochondria. L-Citrulline is then synthesized from carbamoylphosphate and L-ornithine. ${ }^{11,44}$ These latter metabolic pathways allow presumably to regulate, up to a threshold level, the intracellular concentration of $\mathrm{NH}_{3}$, thus limiting its deleterious effect on colonocyte energy metabolism.

Then, it appears that several bacterial metabolites, when present at excessive concentrations, can be considered as luminal metabolic troublemakers, acting on the colonocyte mitochondria. $^{33}$

\section{Bacterial Metabolites and Colonic Epithelial Cell DNA Integrity}

Elevated mitochondrial reactive oxygen species production over the colonocyte capacity to detoxicate them, may damage and produce mutations in mitochondrial DNA, which is in vicinity with the electron transport chain, and which is not protected by histones. ${ }^{45}$ Indeed, an example of mitochondrial DNA mutations observed in colon cancer are mutations in the cytochrome $c$ oxidase (complex IV of the mitochondrial respiratory chain) with associated proton leak and thus decreased energy-conversion efficiency. ${ }^{46}$ Incidentally, mitochondrial electron transport chain complex dysfunction has also been observed in the colonic mucosa from ulcerative colitis patients with both quiescent and active disease. ${ }^{47}$

Hydrogen sulfide was previously reported to be able to alter genomic DNA integrity in intestinal colonic epithelial cells. ${ }^{48}$ However, these results were not confirmed in further experiments, maybe because of different experimental design. Indeed, using both in vivo colonic intraluminal instillation in rats and longer-term culture of human colonic epithelial cells with millimolar concentrations of sodium sulfide up to $3 \mathrm{mmol} / \mathrm{L}$, no effect of this agent on DNA integrity was detected using the sensitive $\gamma \mathrm{H} 2 \mathrm{AX}$ genotoxicity test. ${ }^{17}$

Using the same experimental design, $p$-cresol was found to dose dependently alter the DNA integrity in colonocytes without cytotoxic effects. ${ }^{38}$ Phenol, which is produced by the intestinal microbiota from L-tyrosine, after reacting with nitrite, leads to the formation of the mutagenic compound p-diazoquinone. ${ }^{49}$

Several other bacterial metabolites have been identified as able to alter DNA integrity in colonocytes. Indeed, fecal fecapentaenes, which are produced by the intestinal microbiota presumably from polyunsaturated ether phospholipids, represent potent mutagens toward colon epithelial cell DNA. ${ }^{50}$ Deoxycholic acid produced in the colon by the intestinal microbiota can also act as a DNA-damaging agent. ${ }^{51}$ Although ethanol (which is found at millimolar concentrations in the rat colon ${ }^{16}$ ) is likely not genotoxic by itself for colonic epithelial cells, this compound can be converted to acetaldehyde by the gut microbiota. Acetaldehyde is considered as a potential carcinogenic compound in the rectum. ${ }^{52}$ Spermine, a polyamine produced by the intestinal microbiota and taken up by colonic epithelial cells, ${ }^{53}$ can increase reactive oxygen species production and DNA damage in these cells through its increased catabolism by the spermine oxidase activity in response to enterotoxigenic $B$. fragilis. ${ }^{54}$ Last, $\mathrm{N}$-nitroso compounds, which are formed notably in the colonic luminal content, are viewed as compounds with potential genotoxic effects on colonocytes. ${ }^{55}$ It is then conceivable that long-term exposure of colonic crypt stem cells to excessive DNA-damaging bacterial metabolites may increase the risk of unrepaired DNA lesions in these cells. ${ }^{56}$

\section{Bacterial Metabolites and Colonic Epithelium Proliferation}

Several bacterial metabolites at high concentrations that can be measured in the colonic luminal content have been shown to inhibit the proliferation of human colonocytes. Most of these studies have been done using in vitro experiments with human colonocytes originating from colorectal cancer. Butyrate at millimolar concentrations strongly inhibits human colon adenocarcinoma HT-29 cell proliferation. ${ }^{57}$ It has been recently proposed that differentiated colonocytes, by consuming butyrate, decrease the concentration of this short-chain fatty acid in the vicinity of stem/ progenitor cells in the colonic crypts, protecting these cells from the inhibitory effect of butyrate on their proliferation. ${ }^{58}$

Hydrogen sulfide at millimolar concentrations is able to inhibit dose dependently HT-29 $\mathrm{Glc}^{-1+}$ cell proliferation. ${ }^{34}$ 
In response to pretreatment with the hydrogen sulfide donor NaHS, HT-29 $\mathrm{Glc}^{-/+}$cells increase their glycolytic capacity, presumably as a way-together with reduced proliferation (and thus reduced associated ATP-consuming anabolic pathways) - to maintain their ATP cell content and thus cell viability. ${ }^{34}$ The bacterial metabolite $p$-cresol is also able, in the range of physiological concentrations, to reduce human colonocyte proliferation by accumulating them in the S-cell cycle phase. ${ }^{38}$ Deoxycholic acid is another bacterial metabolite that is able to inhibit intestinal epithelial proliferation at concentrations that are not cytotoxic. ${ }^{59}$ Last, ammonia inhibits proliferation of colonocytes originating from colon cancer, characterized by their inability to metabolize this metabolite, ${ }^{60}$ reinforcing the view that detoxification metabolism in colonocytes can avoid deleterious effects of some bacterial metabolites. Among bacterial metabolites acting on colonic epithelial cell proliferation, the polyamines putrescine and agmatine exert opposite effects, with the former being strictly necessary for colonocyte mitosis, ${ }^{53}$ whereas the second displays an antimitotic effect. ${ }^{61}$

\section{Dietary Compounds, Bacterial Metabolites, and Colonic Epithelial Cell Viability}

Some dietary compounds, and bacterial metabolites derived from them, have been shown to affect colonocyte viability. Such loss of cell viability, independently from the physiological process of fully mature colonocyte apoptosis/ exfoliation, may lead to the so-called process of compensatory hyperproliferation. ${ }^{62}$ An interesting example of a dietary compound that affects colonic epithelial cell viability and induces colon epithelial hyperproliferation is represented by the heme molecule. Heme in meat and fish is mainly present in hemoglobin and myoglobin. Heme is only partly absorbed in the small intestine, with part of it being recovered in the large intestine luminal content. ${ }^{63}$ Heme in vicinity with the colonic surface epithelium exerts cytotoxic effects, resulting in epithelial damage and compensatory hyperproliferation, leading to hyperplasia in a gut microbiota-dependent manner. ${ }^{62,63}$ In addition, heme is genotoxic toward colonic epithelial cells. ${ }^{64}$ These heme characteristics may explain the positive association between the heme intake and the risk of colorectal cancer risk. ${ }^{65}$ However, not all epidemiological studies found correlation between dietary heme consumption and colorectal cancer incidence, ${ }^{66}$ challenging this concept and suggesting that heme may synergize with other dietary components (eg, protein as precursors of amino acid-derived deleterious bacterial metabolites) for the colorectal carcinogenesis process. ${ }^{67}$

At a low milimolar concentration, phenol, another bacterial metabolite, has been shown to significantly impair the viability of human colonocytes. ${ }^{68}$ Last, deoxycholic acid has been reported to be cytotoxic on colonic epithelial cells in addition to its genotoxic effect. ${ }^{69}$

\section{Bacterial Metabolites and Colonic Epithelial Barrier Function}

Some bacterial metabolites have been suspected to affect, either positively or negatively, the colonic epithelial barrier function. For instance, it has been proposed that hydrogen sulfide, by reducing disulfide bonds in mucus, would increase the permeability of the mucous layer to luminal compounds, including the heme compound. ${ }^{62}$

Interestingly, evidence has been presented that perturbed mitochondrial function induced by uncoupling agent in colonic epithelial cells causes intestinal barrier dysfunction, ${ }^{70}$ adding further evidence to the view that altered mitochondrial function participates in alteration of the epithelial integrity.

Conversely, indole, a bacterial metabolite produced from L-tryptophan, has been shown to be beneficial for the colonic epithelium by increasing epithelial cell tightjunction resistance. ${ }^{71}$ Last, butyrate is also recognized as a bacterial metabolite that enhances the intestinal barrier function. $^{72}$

\section{Bacterial Metabolites and Luminal pH}

Several bacterial metabolites, either acidic or alkaline, can affect the colonic luminal $\mathrm{pH}$. Conversely, the luminal $\mathrm{pH}$ can affect the acid/base ratio of several bacterial metabolites.

The $\mathrm{pH}$ of the human cecal content is slightly acidic, ranging from 5.7 to 6.8 , while ranging from 6.1 to 7.5 in the descending colon and rectum. ${ }^{73}$ The $\mathrm{pH}$ at the colonic mucosal surface in healthy subjects is averaging 7.1 in cecum and ascending colon, whereas it ranges from 7.2 to 7.5 in the descending colon and rectum. ${ }^{74}$ The luminal $\mathrm{pH}$ depends on the respective concentrations of a complex mixture of acids and bases in the large intestine content, among which hydrogen and bicarbonate secretion by the colonic mucosa represent important determinants. ${ }^{73}$ Shortchain fatty acids also participate as organic acids, together with other microbiota-derived acidic metabolites (present, however, at much lower concentrations) like branched-chain fatty acids, organic acids (lactate, succinate, and phenylacetate), and hydrogen sulfide. Ammonia intervenes in the luminal $\mathrm{pH}$ as a weak base.

In turn, changes in the luminal $\mathrm{pH}$ may affect the uptake of luminal compounds by colonocytes and then their action on these cells; however, few studies have unfortunately been performed on that specific important topic. For instance, hydrogen sulfide dissociates in solution, yielding hydrosulfide anion with a pKa value equal to $7.04 .^{33}$ Thus, in case of lower luminal $\mathrm{pH}$, the hydrogen sulfide/hydrosulfide anion ratio in the large intestine will increase (Figure 2). Taking into account that hydrogen sulfide, unlike hydrosulfide anion, easily penetrates biological membrane, ${ }^{75}$ one can predict that lower luminal $\mathrm{pH}$ will increase hydrogen 
sulfide concentration, and thus amplify its deleterious effect on colonocyte respiration at excessive concentrations. ${ }^{36}$ The same reasoning can be made regarding butyrate and ammonia. Butyrate, according to its pKa value (4.7), exists predominantly in the anionic dissociated form at the normal colonic $\mathrm{pH}$; this anionic form being transported by the monocarboxylate transporter isoform 1 , which is present in the colonocyte brush-border membranes ${ }^{28,76}$ (Figure 1). Then, at a more acidic luminal $\mathrm{pH}$, the concentration of the anionic form will decrease, resulting in lower uptake of this compound through monocarboxylate transporter isoform 1 by colonocytes, and presumably different impact on these cells. ${ }^{32,77}$ Last, ammonia with a pKa equal to 9.02 is mainly present as $\mathrm{NH}_{4}^{+}$in the colonic luminal content and transported in differentiated colonocytes through dedicated transporters from the RhBG and RhCG families. ${ }^{78}$ A more alkaline luminal $\mathrm{pH}$ will displace the equilibrium in favor of $\mathrm{NH}_{3}$, knowing that this compound is highly diffusible across colonocyte membranes. ${ }^{79}$ Then, increased intracytoplasmic $\mathrm{NH}_{3}$ may penetrate mitochondrial membrane to a higher level, ${ }^{80}$ affecting basal mitochondrial oxygen consumption and butyrate/acetate oxidation in colonocytes. $^{42,43}$

Beyond the influence of luminal $\mathrm{pH}$ on the transport and action of bacterial metabolites inside colonocytes, the modifications of the luminal $\mathrm{pH}$ per se may affect colonic epithelial cell physiology. Interestingly, lower colonic luminal $\mathrm{pH}$ in patients with ulcerative colitis ${ }^{73}$ has been observed. In a model of rodent with chemical induction of colon carcinogenesis, lower luminal $\mathrm{pH}$ is associated with higher tumor yield and increased epithelial cell proliferation. ${ }^{81}$ A low $\mathrm{pH}$ inhibits the synthesis by the intestinal microbiota of the DNA-damaging secondary bile acids ${ }^{82}$ and reduces the activity of luminal proteases. ${ }^{83}$ In addition, acidic extracellular $\mathrm{pH}$ has been shown to shift colorectal cell death from apoptosis to necrosis on exposure to short-chain fatty acids. ${ }^{84}$ Last, low external $\mathrm{pH}$ has been shown to dramatically increase the expression of the multidrug resistance protein in human colon carcinoma cell lines, ${ }^{85}$ rendering these cells more resistant to chemotherapeutic agents. Thus, it appears that a more acidic colonic luminal $\mathrm{pH}$ is associated with both beneficial and deleterious effects on colonocytes; these effects are apparently different according to the status of colonocytes (healthy or neoplasic).

\section{Dietary Compounds, Bacterial Metabolites, and Luminal Osmolarity}

Carbohydrate malabsorption associated with osmotic diarrhea likely depends primarily on the balance between the osmotic force of the carbohydrate incriminated, on the capacity of the microbiota to metabolize this compound, and on the colonic absorptive capacity toward these compounds. The same reasoning can be made regarding the bacterial metabolites, which, depending notably on the food/microbiota composition, and on the transport capacity of colonocytes, may accumulate in the colonic/rectal luminal content and modify luminal osmolarity.

Osmotic strength of the fecal stool in humans is in the range of 321 to $350 \mathrm{mOsm} / \mathrm{L}$. The most common manifestation of carbohydrate malabsorption, that is lactose malabsorption, may provoke osmotic diarrhea ${ }^{86}$ Increased luminal osmolarity has been associated with several effects on colonic epithelial cells in relationship with the epithelial barrier function and mucosal inflammation. In in vitro experiments, hyperosmotic stress induces cell signaling associated with cell survival in colon cancer cells through the osmotic regulator NFAT5. ${ }^{87}$ Hyperosmotic medium increases the expression of SPAK, a protein whose expression in colonocytes is associated with increased epithelial permeability. ${ }^{88}$ In other in vitro experiments with colonic epithelial cells originating from human cancer, hyperosmolarity is able to stimulate the expression of the proinflammatory IL- 8 through NF- $\mathrm{BB}$ activation. ${ }^{89}$ In the rat colon, hypertonic solution increases mucus output. ${ }^{90}$ Hyperosmolarity is able to increase within 2 hours the expression of the cyclooxygenase- 2 gene in human colonocytes, ${ }^{91}$ this enzymatic activity being increased in the colonic inflammation and colonic epithelial carcinogenesis processes. ${ }^{92}$ Last, it has been shown that, in the experimental model of colitis induced in rodents with dextran sulfate sodium, luminal hyperosmolarity in colon plays a major role for mucosal inflammation. ${ }^{93}$ Thus, overall, hyperosmotic environment of colonic epithelial cells appears to be associated with adverse effects in terms of epithelial barrier function and events associated with inflammation. Interestingly, higher fecal values of osmotic strength have been observed in Crohn's disease patients when compared with healthy counterparts. ${ }^{94,95}$

\section{Adaptive Processes in Colonocytes toward Changes of Bacterial Metabolite Concentrations}

Although, as presented above, there is little doubt from in vitro and in vivo experiments that changes in the bacterial metabolite concentrations in proximity to the colonic epithelial cells affect their metabolism, functions, and likely the homeostatic process of epithelium renewal, the predicting of the impact of such changes on the colonic epithelium is not an easy task. Indeed, these compounds, which have been in most cases tested individually, can exert opposite, additive, or synergistic effects on colonocytes; and their effects depend on their respective free and bound luminal concentrations, and on the capacity of colonocytes to metabolize them. The situation is further complicated if we consider the adaptive capacity of colonocytes toward changing luminal environment. For 
Table 1 Some Typical Effects of Bacterial Metabolites on Colonic Epithelial Cells

\begin{tabular}{lll}
\hline Bacterial metabolites & Modified parameters & References \\
\hline Hydrogen sulfide and $p$-cresol & Decreased oxygen consumption & 34,38 \\
Hydrogen sulfide and ammonia & Decreased SCFA oxidation & Aff,42 \\
Phenol, $p$-cresol, acetaldehyde, fecapentanes, and deoxycholic acid & DNA integrity & Decreased cell viability \\
Phenol and deoxycholic acid & Decreased cell proliferation \\
Hydrogen sulfide, $p$-cresol, ammonia, and deoxycholic acid & Increased barrier function \\
Indole and butyrate & Decreased barrier function \\
Hydrogen sulfide &
\end{tabular}

SCFA, short-chain fatty acid.

instance, an increased water content in the colonic lumen is likely to represent, at least in rodent models, a way to avoid sharp increase of bacterial metabolite concentrations in case of increased net production. In fact, in the rat model, highprotein consumption increases the colonic content of shortchain fatty acids ${ }^{16}$ and hydrogen sulfide ${ }^{17}$ when compared with animals consuming a normoproteic isocaloric diet. However, nearly proportional increased water content in the colon of animals fed with the high-protein $\operatorname{diet}^{43}$ attenuates greatly the increased concentrations of these metabolites. Whether this increased water content simply results from increased osmolarity of the colonic content, and/or implies modified water and electrolyte transport, remains to be determined.

Increased detoxification pathways in colonocytes may also allow us to control the intracellular concentrations of deleterious bacterial metabolites like hydrogen sulfide and ammonia. Regarding hydrogen sulfide, it has been shown in the rat model that when the animals are fed for 2 weeks with a high-protein diet, a modest but significant increase of sulfide quinone reductase gene (Sqr) (Figure 2) expression is recorded in colonocytes when compared with normoproteic control animals. ${ }^{17}$ Interestingly, impaired hydrogen sulfide detoxification in intestinal mucosa is associated with Crohn's disease. ${ }^{96}$ Last, a study indicates that the increased concentration of ammonia recorded in the colonic content of rats after high-protein diet consumption is associated with an increased catalytic activity of glutamine synthetase, in colonocytes, presumably allowing increased ammonia detoxification. ${ }^{44}$

\section{Conclusion and Future Prospects}

Mostly from experimental studies with animal models and cell physiology experiments, the idea that changes in the luminal environment of colonic epithelial cells-and notably high concentrations of several bacterial metabolites-affect major aspects of their physiology and metabolism, like energy metabolism, DNA integrity, proliferation, and viability, affecting presumably the process of epithelial renewal, appears to represent a robust proof of concept (Table 1).
One main crucial unresolved question, regarding the effects of genotoxic bacterial metabolites, is related to the concentrations of these compounds in the vicinity of the colonic crypt stem cells, a parameter not easily measurable for obvious technical reasons. Indeed, because the crypt stem cells appear to be the cells at the origin of colorectal cancer, ${ }^{97,98}$ the identification of the luminal compounds at the origin of mutations in these cells, as well as the threshold of concentrations above which genotoxic and cytotoxic effects are expected, would represent a central piece of information in the field. In the same line of thinking, a recent article has shown that the lifetime risk of cancers of different types is well correlated with the total number of divisions of the normal self-renewing cells. ${ }^{99}$ Although this latter correlation allows to partly explain the relatively high frequency of colorectal cancer among other less frequent types of cancers, it does not provide a satisfactory explanation on the fact that groups of individuals migrating from a country with low incidence of colorectal cancer to a country with high incidence meet the incidence of the welcoming country ${ }^{100}$; this suggests an impact of environment (and notably of the luminal environment of colonocytes) on the colorectal carcinogenesis process.

Another crucial point is related to the capacity of the bacterial metabolites to cross the mucus layers before entering the colonocytes. Most of in vitro studies have been performed with colonocytes directly exposed to bacterial metabolites. From that point of view, intraluminal colonic instillation of bacterial metabolites in anesthetized animal models represents an experimental design closer to the physiological situation. ${ }^{17}$

Finally, by better identifying the changes in the luminal environment that increase or decrease the risk of alteration in the normal process of colonic/rectal epithelium renewal and functions, it should become possible to intervene, particularly from a dietary point of view, for limiting the risk of pathology from inflammatory and neoplasic types in this anatomical region.

\section{Acknowledgments}

We thank all of the contributors in the field, notably those who could not be cited herein because of space limitation. 


\section{References}

1. Barker N: Adult intestinal stem cells: critical drivers of epithelial homeostasis and regeneration. Nat Rev Mol Cell Biol 2014, 15: $19-33$

2. Loktionov A: Cell exfoliation in the human colon: myth, reality and implications for colorectal cancer screening. Int J Cancer 2007, 120: 2281-2289

3. Peterson LW, Artis D: Intestinal epithelial cells: regulators of barrier function and immune homeostasis. Nat Rev Immunol 2014, 14: $141-153$

4. Payne CM, Fass R, Bernstein H, Giron J, Bernstein C, Dvorak K, Garewal H: Pathogenesis of diarrhea in the adult: diagnostic challenges and life-threatening conditions. Eur J Gastroenterol Hepatol 2006, 18:1047-1051

5. Terzic J, Grivennikov S, Karin E, Karin M: Inflammation and colon cancer. Gastroenterology 2010, 138:2101-2114e5

6. Boleij A, Tjalsma H: Gut bacteria in health and disease: a survey on the interface between intestinal microbiology and colorectal cancer. Biol Rev Camb Philos Soc 2012, 87:701-730

7. Macfarlane GT, Macfarlane S: Human colonic microbiota: ecology, physiology and metabolic potential of intestinal bacteria. Scand J Gastroenterol Suppl 1997, 222:3-9

8. Duncan SH, Belenguer A, Holtrop G, Johnstone AM, Flint HJ, Lobley GE: Reduced dietary intake of carbohydrates by obese subjects results in decreased concentrations of butyrate and butyrateproducing bacteria in feces. Appl Environ Microbiol 2007, 73: 1073-1078

9. Reddy B, Engle A, Katsifis S, Simi B, Bartram HP, Perrino P, Mahan C: Biochemical epidemiology of colon cancer: effect of types of dietary fiber on fecal mutagens, acid, and neutral sterols in healthy subjects. Cancer Res 1989, 49:4629-4635

10. Windey K, De Preter V, Verbeke K: Relevance of protein fermentation to gut health. Mol Nutr Food Res 2012, 56:184-196

11. Mouille B, Robert V, Blachier F: Adaptative increase of ornithine production and decrease of ammonia metabolism in rat colonocytes after hyperproteic diet ingestion. Am J Physiol Gastrointest Liver Physiol 2004, 287:G344-G351

12. Petry N, Egli I, Chassard C, Lacroix C, Hurrell R: Inulin modifies the bifidobacteria population, fecal lactate concentration, and fecal $\mathrm{pH}$ but does not influence iron absorption in women with low iron status. Am J Clin Nutr 2012, 96:325-331

13. Russell WR, Gratz SW, Duncan SH, Holtrop G, Ince J, Scobbie L, Duncan G, Johnstone AM, Lobley GE, Wallace RJ, Duthie GG, Flint HJ: High-protein, reduced-carbohydrate weight-loss diets promote metabolite profiles likely to be detrimental to colonic health Am J Clin Nutr 2011, 93:1062-1072

14. Zoetendal EG, Akkermans AD, De Vos WM: Temperature gradient gel electrophoresis analysis of 16S rRNA from human fecal samples reveals stable and host-specific communities of active bacteria. Appl Environ Microbiol 1998, 64:3854-3859

15. David LA, Maurice CF, Carmody RN, Gootenberg DB, Button JE, Wolfe BE, Ling AV, Devlin AS, Varma Y, Fischbach MA, Biddinger SB, Dutton RJ, Turnbaugh PJ: Diet rapidly and reproducibly alters the human gut microbiome. Nature 2014, 505:559-563

16. Liu X, Blouin JM, Santacruz A, Lan A, Andriamihaja M, Wilkanowicz S, Benetti PH, Tome D, Sanz Y, Blachier F, Davila AM: High-protein diet modifies colonic microbiota and luminal environment but not colonocyte metabolism in the rat model: the increased luminal bulk connection. Am J Physiol Gastrointest Liver Physiol 2014, 307:G459-G470

17. Beaumont M, Andriamihaja M, Lan A, Khodorova N, Audebert M, Blouin JM, Grauso M, Lancha L, Benetti PH, Benamouzig R, Tome D, Bouillaud F, Davila AM, Blachier F: Detrimental effects for colonocytes of an increased exposure to luminal hydrogen sulfide: the adaptive response. Free Radic Biol Med 2016, 93:155-164
18. Bjerrum JT, Wang Y, Hao F, Coskun M, Ludwig C, Gunther U, Nielsen OH: Metabonomics of human fecal extracts characterize ulcerative colitis, Crohn's disease and healthy individuals. Metabolomics 2015, 11:122-133

19. Vipperla K, O’Keefe SJ: Diet, microbiota, and dysbiosis: a "recipe" for colorectal cancer. Food Funct 2016, 7:1731-1740

20. Sears CL, Garrett WS: Microbes, microbiota, and colon cancer. Cell Host Microbe 2014, 15:317-328

21. Blachier F, Boutry C, Bos C, Tome D: Metabolism and functions of L-glutamate in the epithelial cells of the small and large intestines. Am J Clin Nutr 2009, 90:814S-821S

22. Ward JB, Keely SJ, Keely SJ: Oxygen in the regulation of intestinal epithelial transport. J Physiol 2014, 592:2473-2489

23. Albenberg L, Esipova TV, Judge CP, Bittinger K, Chen J, Laughlin A, Grunberg S, Baldassano RN, Lewis JD, Li H, Thom SR, Bushman FD, Vinogradov SA, Wu GD: Correlation between intraluminal oxygen gradient and radial partitioning of intestinal microbiota. Gastroenterology 2014, 147:1055-1063e8

24. Espey MG: Role of oxygen gradients in shaping redox relationships between the human intestine and its microbiota. Free Radic Biol Med 2013, 55:130-140

25. Colgan SP, Taylor CT: Hypoxia: an alarm signal during intestinal inflammation. Nat Rev Gastroenterol Hepatol 2010, 7:281-287

26. Yao KS, Xanthoudakis S, Curran T, O'Dwyer PJ: Activation of AP-1 and of a nuclear redox factor, Ref-1, in the response of HT29 colon cancer cells to hypoxia. Mol Cell Biol 1994, 14:5997-6003

27. Bunn HF, Poyton RO: Oxygen sensing and molecular adaptation to hypoxia. Physiol Rev 1996, 76:839-885

28. Hamer HM, Jonkers D, Venema K, Vanhoutvin S, Troost FJ, Brummer RJ: Review article: the role of butyrate on colonic function. Aliment Pharmacol Ther 2008, 27:104-119

29. Blachier F, Mariotti F, Huneau JF, Tome D: Effects of amino acidderived luminal metabolites on the colonic epithelium and physiopathological consequences. Amino Acids 2007, 33:547-562

30. Roediger WE: Utilization of nutrients by isolated epithelial cells of the rat colon. Gastroenterology 1982, 83:424-429

31. Thibault R, Blachier F, Darcy-Vrillon B, de Coppet P, Bourreille A, Segain JP: Butyrate utilization by the colonic mucosa in inflammatory bowel diseases: a transport deficiency. Inflamm Bowel Dis 2010, 16: 684-695

32. Andriamihaja M, Chaumontet C, Tome D, Blachier F: Butyrate metabolism in human colon carcinoma cells: implications concerning its growth-inhibitory effect. J Cell Physiol 2009, 218:58-65

33. Blachier F, Davila AM, Mimoun S, Benetti PH, Atanasiu C, Andriamihaja M, Benamouzig R, Bouillaud F, Tome D: Luminal sulfide and large intestine mucosa: friend or foe? Amino Acids 2010, 39:335-347

34. Leschelle X, Goubern M, Andriamihaja M, Blottiere HM, Couplan E, Gonzalez-Barroso MD, Petit C, Pagniez A, Chaumontet C, Mignotte B, Bouillaud F, Blachier F: Adaptative metabolic response of human colonic epithelial cells to the adverse effects of the luminal compound sulfide. Biochim Biophys Acta 2005, 1725:201-212

35. Goubern M, Andriamihaja M, Nubel T, Blachier F, Bouillaud F: Sulfide, the first inorganic substrate for human cells. FASEB J 2007, 21:1699-1706

36. Mimoun S, Andriamihaja M, Chaumontet C, Atanasiu C, Benamouzig R, Blouin JM, Tome D, Bouillaud F, Blachier F: Detoxification of $\mathrm{H}(2) \mathrm{S}$ by differentiated colonic epithelial cells: implication of the sulfide oxidizing unit and of the cell respiratory capacity. Antioxid Redox Signal 2012, 17:1-10

37. Szabo C, Coletta C, Chao C, Modis K, Szczesny B, Papapetropoulos A, Hellmich MR: Tumor-derived hydrogen sulfide, produced by cystathionine-beta-synthase, stimulates bioenergetics, cell proliferation, and angiogenesis in colon cancer. Proc Natl Acad Sci U S A 2013, 110:12474-12479

38. Andriamihaja M, Lan A, Beaumont M, Audebert M, Wong X, Yamada K, Yin Y, Tome D, Carrasco-Pozo C, Gotteland M, Kong X, 
Blachier F: The deleterious metabolic and genotoxic effects of the bacterial metabolite p-cresol on colonic epithelial cells. Free Radic Biol Med 2015, 85:219-227

39. Brand MD: The sites and topology of mitochondrial superoxide production. Exp Gerontol 2010, 45:466-472

40. Muller FL, Liu Y, Van Remmen H: Complex III releases superoxide to both sides of the inner mitochondrial membrane. J Biol Chem 2004, 279:49064-49073

41. Radi R: Peroxynitrite, a stealthy biological oxidant. J Biol Chem 2013, 288:26464-26472

42. Cremin JD Jr, Fitch MD, Fleming SE: Glucose alleviates ammoniainduced inhibition of short-chain fatty acid metabolism in rat colonic epithelial cells. Am J Physiol Gastrointest Liver Physiol 2003, 285:G105-G114

43. Andriamihaja M, Davila AM, Eklou-Lawson M, Petit N, Delpal S, Allek F, Blais A, Delteil C, Tome D, Blachier F: Colon luminal content and epithelial cell morphology are markedly modified in rats fed with a high-protein diet. Am J Physiol Gastrointest Liver Physiol 2010, 299:G1030-G1037

44. Eklou-Lawson M, Bernard F, Neveux N, Chaumontet C, Bos C, Davila-Gay AM, Tome D, Cynober L, Blachier F: Colonic luminal ammonia and portal blood L-glutamine and L-arginine concentrations: a possible link between colon mucosa and liver ureagenesis. Amino Acids 2009, 37:751-760

45. Verma M, Kagan J, Sidransky D, Srivastava S: Proteomic analysis of cancer-cell mitochondria. Nat Rev Cancer 2003, 3:789-795

46. Namslauer I, Brzezinski P: A mitochondrial DNA mutation linked to colon cancer results in proton leaks in cytochrome c oxidase. Proc Natl Acad Sci U S A 2009, 106:3402-3407

47. Santhanam S, Rajamanickam S, Motamarry A, Ramakrishna BS, Amirtharaj JG, Ramachandran A, Pulimood A, Venkatraman A: Mitochondrial electron transport chain complex dysfunction in the colonic mucosa in ulcerative colitis. Inflamm Bowel Dis 2012, 18: $2158-2168$

48. Attene-Ramos MS, Nava GM, Muellner MG, Wagner ED, Plewa MJ, Gaskins HR: DNA damage and toxicogenomic analyses of hydrogen sulfide in human intestinal epithelial FHs 74 Int cells. Environ Mol Mutagen 2010, 51:304-314

49. Kikugawa K, Kato T: Formation of a mutagenic diazoquinone by interaction of phenol with nitrite. Food Chem Toxicol 1988, 26: 209-214

50. Hinzman MJ, Novotny C, Ullah A, Shamsuddin AM: Fecal mutagen fecapentaene-12 damages mammalian colon epithelial DNA. Carcinogenesis $1987,8: 1475-1479$

51. Hamer HM, De Preter V, Windey K, Verbeke K: Functional analysis of colonic bacterial metabolism: relevant to health? Am J Physiol Gastrointest Liver Physiol 2012, 302:G1-G9

52. Seitz HK, Simanowski UA, Garzon FT, Rideout JM, Peters TJ, Koch A, Berger MR, Einecke H, Maiwald M: Possible role of acetaldehyde in ethanol-related rectal cocarcinogenesis in the rat. Gastroenterology 1990, 98:406-413

53. Blachier F, Davila AM, Benamouzig R, Tome D: Channelling of arginine in $\mathrm{NO}$ and polyamine pathways in colonocytes and consequences. Front Biosci (Landmark Ed) 2011, 16:1331-1343

54. Goodwin AC, Destefano Shields CE, Wu S, Huso DL, Wu X, Murray-Stewart TR, Hacker-Prietz A, Rabizadeh S, Woster PM, Sears CL, Casero RA Jr: Polyamine catabolism contributes to enterotoxigenic Bacteroides fragilis-induced colon tumorigenesis. Proc Natl Acad Sci U S A 2011, 108:15354-15359

55. Nyangale EP, Mottram DS, Gibson GR: Gut microbial activity, implications for health and disease: the potential role of metabolite analysis. J Proteome Res 2012, 11:5573-5585

56. Gill CI, Rowland IR: Diet and cancer: assessing the risk. Br J Nutr 2002, 88(Suppl 1):S73-S87

57. Gamet L, Daviaud D, Denis-Pouxviel C, Remesy C, Murat JC: Effects of short-chain fatty acids on growth and differentiation of the human colon-cancer cell line HT29. Int J Cancer 1992, 52:286-289
58. Kaiko GE, Ryu SH, Koues OI, Collins PL, Solnica-Krezel L, Pearce EJ, Pearce EL, Oltz EM, Stappenbeck TS: The colonic crypt protects stem cells from microbiota-derived metabolites. Cell 2016, $165: 1708-1720$

59. Dossa AY, Escobar O, Golden J, Frey MR, Ford HR, Gayer CP: Bile acids regulate intestinal cell proliferation by modulating EGFR and FXR signaling. Am J Physiol Gastrointest Liver Physiol 2016, 310: G81-G92

60. Mouille B, Delpal S, Mayeur C, Blachier F: Inhibition of human colon carcinoma cell growth by ammonia: a non-cytotoxic process associated with polyamine synthesis reduction. Biochim Biophys Acta 2003, 1624:88-97

61. Mayeur C, Veuillet G, Michaud M, Raul F, Blottiere HM, Blachier F: Effects of agmatine accumulation in human colon carcinoma cells on polyamine metabolism, DNA synthesis and the cell cycle. Biochim Biophys Acta 2005, 1745:111-123

62. Ijssennagger N, Belzer C, Hooiveld GJ, Dekker J, van Mil SW, Muller M, Kleerebezem M, van der Meer R: Gut microbiota facilitates dietary heme-induced epithelial hyperproliferation by opening the mucus barrier in colon. Proc Natl Acad Sci U S A 2015, 112: 10038-10043

63. Bastide NM, Chenni F, Audebert M, Santarelli RL, Tache S, Naud N, Baradat M, Jouanin I, Surya R, Hobbs DA, Kuhnle GG, RaymondLetron I, Gueraud F, Corpet DE, Pierre FH: A central role for heme iron in colon carcinogenesis associated with red meat intake. Cancer Res 2015, 75:870-879

64. Glei M, Klenow S, Sauer J, Wegewitz U, Richter K, Pool-Zobel BL: Hemoglobin and hemin induce DNA damage in human colon tumor cells HT29 clone 19A and in primary human colonocytes. Mutat Res 2006, 594:162-171

65. Bastide NM, Pierre FH, Corpet DE: Heme iron from meat and risk of colorectal cancer: a meta-analysis and a review of the mechanisms involved. Cancer Prev Res (Phila) 2011, 4:177-184

66. Zhang X, Giovannucci EL, Smith-Warner SA, Wu K, Fuchs CS, Pollak M, Willett WC, Ma J: A prospective study of intakes of zinc and heme iron and colorectal cancer risk in men and women. Cancer Causes Control 2011, 22:1627-1637

67. Kim E, Coelho D, Blachier F: Review of the association between meat consumption and risk of colorectal cancer. Nutr Res 2013, 33: 983-994

68. Pedersen G, Brynskov J, Saermark T: Phenol toxicity and conjugation in human colonic epithelial cells. Scand J Gastroenterol 2002, 37: $74-79$

69. Barrasa JI, Olmo N, Lizarbe MA, Turnay J: Bile acids in the colon, from healthy to cytotoxic molecules. Toxicol In Vitro 2013, 27: 964-977

70. Wang A, Keita AV, Phan V, McKay CM, Schoultz I, Lee J, Murphy MP, Fernando M, Ronaghan N, Balce D, Yates R, Dicay M, Beck PL, MacNaughton WK, Soderholm JD, McKay DM: Targeting mitochondria-derived reactive oxygen species to reduce epithelial barrier dysfunction and colitis. Am J Pathol 2014, 184:2516-2527

71. Bansal T, Alaniz RC, Wood TK, Jayaraman A: The bacterial signal indole increases epithelial-cell tight-junction resistance and attenuates indicators of inflammation. Proc Natl Acad Sci U S A 2010, 107: 228-233

72. Peng L, Li ZR, Green RS, Holzman IR, Lin J: Butyrate enhances the intestinal barrier by facilitating tight junction assembly via activation of AMP-activated protein kinase in Caco-2 cell monolayers. J Nutr 2009, 139:1619-1625

73. Nugent SG, Kumar D, Rampton DS, Evans DF: Intestinal luminal pH in inflammatory bowel disease: possible determinants and implications for therapy with aminosalicylates and other drugs. Gut 2001, 48: $571-577$

74. McDougall CJ, Wong R, Scudera P, Lesser M, DeCosse JJ: Colonic mucosal pH in humans. Dig Dis Sci 1993, 38:542-545

75. Reiffenstein RJ, Hulbert WC, Roth SH: Toxicology of hydrogen sulfide. Annu Rev Pharmacol Toxicol 1992, 32:109-134 
76. Cuff MA, Shirazi-Beechey SP: The importance of butyrate transport to the regulation of gene expression in the colonic epithelium. Biochem Soc Trans 2004, 32:1100-1102

77. Donohoe DR, Collins LB, Wali A, Bigler R, Sun W, Bultman SJ: The Warburg effect dictates the mechanism of butyrate-mediated histone acetylation and cell proliferation. Mol Cell 2012, 48:612-626

78. Handlogten ME, Hong SP, Zhang L, Vander AW, Steinbaum ML, Campbell-Thompson M, Weiner ID: Expression of the ammonia transporter proteins $\mathrm{Rh} \mathrm{B}$ glycoprotein and $\mathrm{Rh} \mathrm{C}$ glycoprotein in the intestinal tract. Am J Physiol Gastrointest Liver Physiol 2005, 288: G1036-G1047

79. Cohen RM, Stephenson RL, Feldman GM: Bicarbonate secretion modulates ammonium absorption in rat distal colon in vivo. Am J Physiol 1988, 254:F657-F667

80. Soria LR, Fanelli E, Altamura N, Svelto M, Marinelli RA, Calamita G: Aquaporin-8-facilitated mitochondrial ammonia transport. Biochem Biophys Res Commun 2010, 393:217-221

81. Jacobs LR, Lupton JR: Relationship between colonic luminal pH, cell proliferation, and colon carcinogenesis in 1,2-dimethylhydrazine treated rats fed high fiber diets. Cancer Res 1986, 46:1727-1734

82. Christl SU, Bartram HP, Paul A, Kelber E, Scheppach W, Kasper H: Bile acid metabolism by colonic bacteria in continuous culture: effects of starch and pH. Ann Nutr Metab 1997, 41:45-51

83. De Preter V, Hamer HM, Windey K, Verbeke K: The impact of preand/or probiotics on human colonic metabolism: does it affect human health? Mol Nutr Food Res 2011, 55:46-57

84. Lan A, Lagadic-Gossmann D, Lemaire C, Brenner C, Jan G: Acidic extracellular $\mathrm{pH}$ shifts colorectal cancer cell death from apoptosis to necrosis upon exposure to propionate and acetate, major end-products of the human probiotic propionibacteria. Apoptosis 2007, 12: $573-591$

85. Wei LY, Roepe PD: Low external $\mathrm{pH}$ and osmotic shock increase the expression of human MDR protein. Biochemistry 1994, 33: 7229-7238

86. Hammer HF, Hammer J: Diarrhea caused by carbohydrate malabsorption. Gastroenterol Clin North Am 2012, 41:611-627

87. Chen M, Sastry SK, O'Connor KL: Src kinase pathway is involved in NFAT5-mediated S100A4 induction by hyperosmotic stress in colon cancer cells. Am J Physiol Cell Physiol 2011, 300:C1155-C1163

88. Yan Y, Dalmasso G, Nguyen HT, Obertone TS, Sitaraman SV, Merlin D: Ste20-related proline/alanine-rich kinase (SPAK) regulated transcriptionally by hyperosmolarity is involved in intestinal barrier function. PLoS One 2009, 4:e5049

89. Nemeth ZH, Deitch EA, Szabo C, Hasko G: Hyperosmotic stress induces nuclear factor-kappaB activation and interleukin- 8 production in human intestinal epithelial cells. Am J Pathol 2002, 161: 987-996

90. Rubsamen K, Hornicke H: Influence of osmolality, short chain fatty acids and deoxycholic acid on mucus secretion in the rat colon. Pflugers Arch 1982, 395:306-311

91. Arbabi S, Rosengart MR, Garcia I, Jelacic S, Maier RV: Epithelial cyclooxygenase-2 expression: a model for pathogenesis of colon cancer. J Surg Res 2001, 97:60-64

92. Danese S, Mantovani A: Inflammatory bowel disease and intestinal cancer: a paradigm of the Yin-Yang interplay between inflammation and cancer. Oncogene 2010, 29:3313-3323

93. Schwartz L, Abolhassani M, Pooya M, Steyaert JM, Wertz X, Israel M, Guais A, Chaumet-Riffaud P: Hyperosmotic stress contributes to mouse colonic inflammation through the methylation of protein phosphatase 2A. Am J Physiol Gastrointest Liver Physiol 2008, 295:G934-G941

94. Schilli R, Breuer RI, Klein F, Dunn K, Gnaedinger A, Bernstein J, Paige M, Kaufman M: Comparison of the composition of faecal fluid in Crohn's disease and ulcerative colitis. Gut 1982, 23:326-332

95. Vernia P, Gnaedinger A, Hauck W, Breuer RI: Organic anions and the diarrhea of inflammatory bowel disease. Dig Dis Sci 1988, 33: $1353-1358$

96. Arijs I, Vanhove W, Rutgeerts P, Schuit F, Verbeke K, De Preter V: Decreased mucosal sulfide detoxification capacity in patients with Crohn's disease. Inflamm Bowel Dis 2013, 19:E70-E72

97. Barker N, Ridgway RA, van Es JH, van de Wetering M, Begthel H, van den Born M, Danenberg E, Clarke AR, Sansom OJ, Clevers H: Crypt stem cells as the cells-of-origin of intestinal cancer. Nature 2009, 457:608-611

98. Ricci-Vitiani L, Fabrizi E, Palio E, De Maria R: Colon cancer stem cells. J Mol Med (Berl) 2009, 87:1097-1104

99. Tomasetti C, Vogelstein B: Cancer etiology: variation in cancer risk among tissues can be explained by the number of stem cell divisions. Science 2015, 347:78-81

100. Flood DM, Weiss NS, Cook LS, Emerson JC, Schwartz SM, Potter JD: Colorectal cancer incidence in Asian migrants to the United States and their descendants. Cancer Causes Control 2000, 11:403-411 